\title{
Airway re-narrowing following deep inspiration in asthmatic and nonasthmatic subjects
}

\author{
C.M. Salome, C.W. Thorpe, C. Diba, N.J. Brown, N. Berend, G.G. King
}

Airway re-narrowing following deep inspiration in asthmatic and nonasthmatic subjects. C.M. Salome, C.W. Thorpe, C. Diba, N.J. Brown, N. Berend, G.G. King. (C)RS Journals Ltd 2003.

ABSTRACT: After bronchoconstriction, deep inspiration (DI) causes dilatation followed by airway re-narrowing. Re-narrowing may be faster in asthmatic than nonasthmatic subjects. This study investigated the relationship between re-narrowing and the magnitude of both DI-induced dilatation and the volume-dependence of respiratory system resistance ( $R \mathrm{rs})$ during tidal breathing.

In 25 asthmatic and 18 nonasthmatic subjects the forced oscillation technique was used to measure $R$ rs at baseline and after methacholine challenge, during 1 min of tidal breathing, followed by DI to total lung capacity (TLC) and passive return to functional residual capacity (FRC). Dilatation was measured as the decrease in $R$ rs between end tidal inspiration and TLC, re-narrowing as $R$ rs at FRC immediately after DI, as per cent $R$ rs at end-tidal expiration, and volume dependent tidal fluctuation as the difference between mean $R$ rs at end-expiration and end-inspiration.

Asthmatic subjects had greater re-narrowing, less dilatation, and greater tidal fluctuations both at baseline and after challenge. Re-narrowing correlated with baseline tidal fluctuation and inversely with dilatation. Both baseline tidal fluctuation and dilatation were significant independent predictors of re-narrowing.

Following deep inspiration-induced dilatation, faster airway re-narrowing in asthmatic than nonasthmatic subjects is associated not only with reduced deep inspiration-induced dilatation but also with some property of the airways that is detectable prior to challenge as an increased volume dependence of resistance.

Eur Respir J 2003; 22: 62-68.
Woolcock Institute of Medical Research and Cooperative Research Centre for Asthma, University of Sydney, Australia.

Correspondence: C. Salome, Woolcock Institute of Medical Research, Level 9, Building 82, Royal Prince Alfred Hospital, Camperdown 2050, Australia.

Fax: 61295506115

E-mail: cms@woolcock.org.au

Keywords: Airway re-narrowing asthma

deep inspiration

forced oscillation technique

velocity of shortening

Received: April 102003

Accepted: April 212003

This study was supported by the National Health and Medical Research Council (grant no. 153809) and the Cooperative Research Centre for Asthma (project 12a).
It is well recognised that the response of the airways to deep inspiration (DI) differs in asthmatic and nonasthmatic subjects. Following airway narrowing induced by inhaled methacholine, DI causes dilatation of the airways in both asthmatic and nonasthmatic subjects. However, the magnitude of the dilatation is usually less in asthmatic than in nonasthmatic subjects $[1,2]$. It has been suggested that the inability of DI to overcome bronchoconstriction is a fundamental abnormality of asthma, and could contribute to airway hyperresponsiveness [1].

The amount of residual dilatation measured after a DI is likely to be determined both by the degree to which the airways distend in response to the inflationary pressure of a DI and by the rate at which they re-narrow following the release of the distending force. After a single DI, it can take more than a minute for the airways of a healthy subject to renarrow to pre-DI calibre [3]. Using the forced oscillation technique to measure airway resistance continuously throughout a DI, JENSEN et al. [4] measured the extent of both dilatation and re-narrowing, and found that asthmatic subjects both dilated less and re-narrowed more than healthy subjects. They concluded that these differences were attributable to differences in the behaviour of airway smooth muscle (ASM), most likely due to an increase in the stiffness of asthmatic ASM making it unresponsive to stretch. These findings imply that there is an inverse correlation between the magnitude of the DI-induced bronchodilatation and the extent of re-narrowing, though this was not formally tested.

The relationship between re-narrowing and other factors that may be associated with ASM stiffness, such as the periodic stretching of the airways during tidal breathing, has also not been investigated. FREDBERG et al. [5] have shown that small oscillations of ASM, of approximately the same magnitude as occur during tidal breathing, disrupt myosin binding and prevent the cross-bridges from "freezing" into a latch state. They suggest that this periodic perturbation of myosin binding is an essential prerequisite for maintaining ASM flexibility, and that asthmatic airways may be characterised by the loss of this dynamic equilibrium. Thus, subjects with small intra-breath fluctuations in airway calibre during tidal breathing may have stiffer ASM and more rapid re-narrowing than those with larger fluctuations.

The aim of this study was to compare airway re-narrowing following DI-induced dilatation in asthmatic and nonasthmatic subjects, and to determine the relationship between re-narrowing and both the magnitude of DI-induced dilatation and the magnitude of volume-dependent fluctuations in airway calibre during tidal breathing. To do this, the forced oscillation technique was used to continuously measure airway resistance in asthmatic and nonasthmatic subjects before and after methacholine challenge, during both tidal breathing and DI. 


\section{Methods}

\section{Subjects and study design}

Subjects were recruited from the Asthma Centre of the Institute of Respiratory Medicine and from staff and students at the Institute of Respiratory Medicine and the University of Sydney, Australia. Asthmatic subjects had a prior diagnosis of asthma, according to American Thoracic Society criteria, were taking regular treatment to control asthmatic symptoms and had airway hyperresponsiveness to methacholine. Nonasthmatic subjects had no history of respiratory disease, no regular past or current treatment for respiratory disease and normal airway responsiveness. Subjects completed a questionnaire about asthma symptoms, had skin-prick tests to a panel of 14 common aeroallergens and underwent lung function testing before and after methacholine challenge. The Human Ethics Committee of the University of Sydney approved the study and all subjects gave written informed consent.

\section{Airway responsiveness to methacholine}

Airway responsiveness to methacholine (ICN Pharmaceuticals Inc., Costa Mesa, CA, USA) was measured in asthmatic subjects using the method of YAN et al. [6], and in nonasthmatic subjects using a modification of the method of CHAI et al. [7, 8]. Doses ranged 0.05-12.2 $\mu \mathrm{mol}$ in asthmatics and $0.15-199 \mu \mathrm{mol}$ in nonasthmatics. Challenge ceased when the forced expiratory volume in one second (FEV1) fell by $20 \%$ or the maximum dose was administered. Short-acting $\beta$-agonists were withheld for $6 \mathrm{~h}$ and long-acting $\beta$-agonists for $24 \mathrm{~h}$ prior to testing. Dose-response ratio (DRR), calculated as the $\%$ fall FEV1 $\mu$ mol methacholine at the last dose, was recorded as a measure of airway responsiveness [9, 10]. Subjects with DRR $\geqslant 1.6 \%$ fall (equivalent to provocative concentration causing a $20 \%$ fall in FEV1 $\leqslant 12.2 \mu \mathrm{mol}$ ) were defined as having airway hyperresponsiveness.

\section{Measurement and data processing of airway resistance}

Resistance of the respiratory system (Rrs) was measured continuously using the forced oscillation technique with an applied oscillation of $6 \mathrm{~Hz}$. Rrs was measured at baseline and after the methacholine challenge, before the spirometric function was measured. Measurements of Rrs were made during 1 min of tidal breathing, followed by a slow DI to total lung capacity (TLC) and a passive exhalation back to tidal breathing for another minute. Subjects were instructed not to hold their breath at TLC.

The forced oscillation device was developed by the authors following the same general design as systems described previously, and measured flow and pressure at the mouth during tidal breathing. The device was calibrated using calibration tubes of known resistance. The subject breathed through an antibacterial filter, with resistance of $0.4 \mathrm{~cm} \mathrm{H}_{2} \mathrm{O} \cdot \mathrm{L}^{-1} \cdot \mathrm{s}^{-1}$, which was subtracted from the ensuing measurements, to an exhaust port while a $6 \mathrm{~Hz}$ oscillation was applied. Flow was measured using a $50 \mathrm{~mm}$ diameter Fleisch pneumotachograph (Vitalograph Ltd, Maids Moreton, UK), with differential pressure measured using a $\pm 2.5 \mathrm{~cm} \mathrm{H}_{2} \mathrm{O}$ solid-state pressure transducer (Sursense DCAL4; Honeywell Sensing and Control, Milpitas, CA, USA). Mouth pressure was measured using a similar transducer that had a higher range $\left( \pm 12.5 \mathrm{cmH}_{2} \mathrm{O}\right)$. All data processing was implemented as digital signal processing operations in Matlab numerical processing language (The Mathworks, Natick, MA, USA). The pressure and flow signals were low-pass filtered at $25 \mathrm{~Hz}$ and sampled at $300 \mathrm{~Hz}$ with a 16-bit A/D converter. Signals were first bandpass filtered using a bandwith of $2 \mathrm{~Hz}$ centred around $6 \mathrm{~Hz}$ and divided into segments of $1 / 6 \mathrm{~s}$ from which the impedance was calculated via division in the frequency domain. For the purposes of the results presented here, only the real part of the impedance was kept, with the procedure providing six measurements of Rrs per second. Any extreme $R$ rs values, which may occur if the glottis closes or the seal around the mouthpiece is lost during testing, were automatically identified and excluded from subsequent processing.

The flow signal was separately low-pass filtered at $2 \mathrm{~Hz}$ with a filter having the same time delay as the bandpass filter, in order to maintain the phase relationship between the resistance and breathing flow signals. Integrating this flow signal provided an estimate of the breathing volume, which was adjusted for any drift by subtracting a straight line fit through all of the end-expiratory points in the recording. Since $R$ rs is influenced by the magnitude of flow, the authors used Rrs measurements at instants of zero flow, i.e. at end inspiration ( $R \mathrm{rs}$,insp) and at end-expiration $(R \mathrm{rs}$,exp), which were also automatically identified during the analysis procedure.

\section{Data analyses}

Spirometric values are reported as a percentage of the predicted values of MORRIS et al. [11]. The principal outcome variables for $R$ rs were calculated from measurements as illustrated in figure 1 . The mean of all $R$ rs values obtained over $1 \mathrm{~min}$ of tidal breathing ( $R \mathrm{rs}$, mean) was calculated as overall measure of resistance at baseline and after challenge, and values are reported as a percentage of the predicted values of PASKER et al. [12]. Rrs,insp and Rrs,exp resistance was calculated over $1 \mathrm{~min}$ of tidal breathing before DI. DIinduced dilatation was calculated as the difference between $R$ rs,insp and resistance of the respiratory system at TLC (Rrs,TLC), and expressed as a percentage of Rrs,insp. Renarrowing was calculated as $R$ rs at functional residual capacity (FRC) immediately after the DI (Rrs,postDI), expressed as a percentage of $R$ rs,exp. Rate of re-narrowing was calculated from the $R$ rs, exp values as the time from

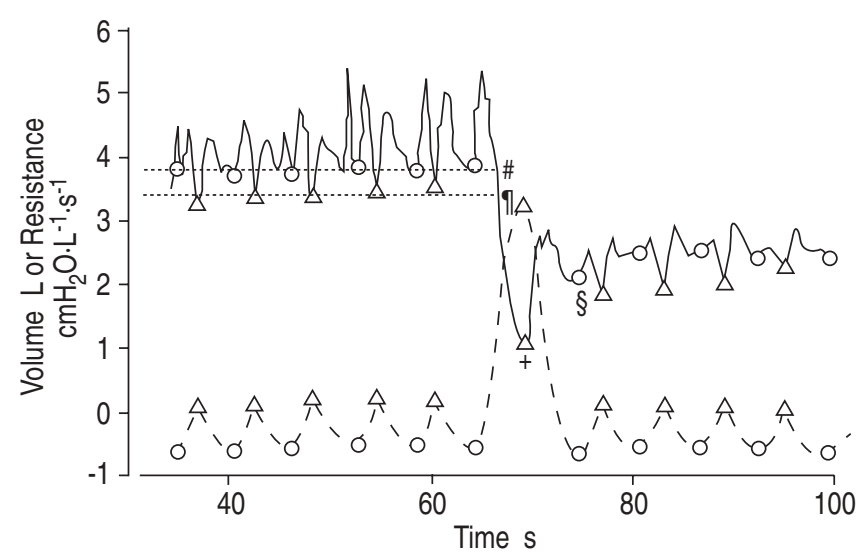

Fig. 1.-Typical trace of respiratory system volume (- - ) and resistance $(-)$ from a single subject, showing values at end-inspiration $(\triangle)$ and end-expiration $(\bigcirc)$. Mean respiratory system resistance at end-expiration $\left(^{\#}\right)$ and end-inspiration $\left(^{\oplus}\right)$, as well as the resistance at total lung capacity $\left({ }^{+}\right)$following deep inspiration and at the first end-expiration following the deep inspiration $\left({ }^{\S}\right)$ were used to calculate dilatation, re-narrowing and tidal fluctuation in respiratory system resistance, as described in the text. 
maximum lung inflation during DI to the first point at which $R$ rs,exp $\geqslant 90 \%$ mean pre-DI $R$ rs,exp. Tidal fluctuation in $R$ rs was calculated as the difference between $R$ rs,exp and $R$ rs,insp.

Data are summarised as mean $\pm 95 \%$ confidence intervals unless otherwise specified. Between group differences were examined using unpaired t-tests. Correlations between variables were determined by Spearmans correlation coefficient (Rs). The relationships between tidal fluctuations in airway calibre, DI-induced dilatation, re-narrowing and log DRR were examined using multiple linear regression, with a stepwise, backward elimination technique.

\section{Results}

Table 1 shows the characteristics of the 25 asthmatic and 18 nonasthmatic subjects, and the changes in lung function associated with the methacholine challenges. All but three nonasthmatic and four asthmatic subjects were lifetime nonsmokers, and no subject had smoked within the last $10 \mathrm{yrs}$. The asthmatic subjects were older, more atopic, had more airway inflammation, indicated by higher exhaled nitric oxide, and more airway obstruction, indicated by both higher baseline Rrs and lower FEV1, than the nonasthmatic subjects. Their asthma was mild or well controlled, with the mean FEV1 value for the group in the predicted range. Altogether, 13 subjects were taking regular inhaled corticosteroid treatment and three of those also required regular long-acting $\beta$-agonist treatment. There were no significant differences between asthmatic and nonasthmatic subjects in the magnitude of increase in $R$ rs, mean following methacholine, although the dose of methacholine was much larger in the nonasthmatic subjects. At baseline there were no significant differences in tidal volumes or inspiratory capacity. Methacholine challenge had no effect on tidal volumes, though the decrease in inspiratory capacity was greater in asthmatic subjects than in nonasthmatic subjects $(18.5 \pm 4.8 \%$ versus $9.8 \pm 5.4 \%, \mathrm{p}=0.03)$.

After methacholine challenge, DI caused significant dilatation in both asthmatic and nonasthmatic subjects (fig. 2a), and the magnitude of dilatation was significantly greater in nonasthmatic subjects $(\mathrm{p}=0.014)$. In the asthmatic subjects, $R \mathrm{rs}$,insp was $3.9 \pm 0.6 \mathrm{cmH}_{2} \mathrm{O} \pm \mathrm{L}^{-1} \cdot \mathrm{s}^{-1}$. At total lung capacity during DI, mean Rrs (Rrs,TLC) was $2.0 \pm 0.3 \mathrm{cmH}_{2} \mathrm{O} \cdot \mathrm{L}^{-1} \cdot \mathrm{s}^{-1}$, a DI-induced dilatation of $46 \pm 7 \%,(\mathrm{p}<0.001)$. In the nonasthmatic subjects, mean $R \mathrm{rs}$,insp was $3.7 \pm 0.8 \mathrm{cmH} \mathrm{CH}_{2} \mathrm{O} \cdot \mathrm{L}^{-1} \cdot \mathrm{s}^{-1}$ and mean $R \mathrm{rs}$, TLC was $1.3 \pm 0.2 \mathrm{cmH}_{2} \mathrm{O} \cdot \mathrm{L}^{-1} \cdot \mathrm{s}^{-1}$, a DI-induced
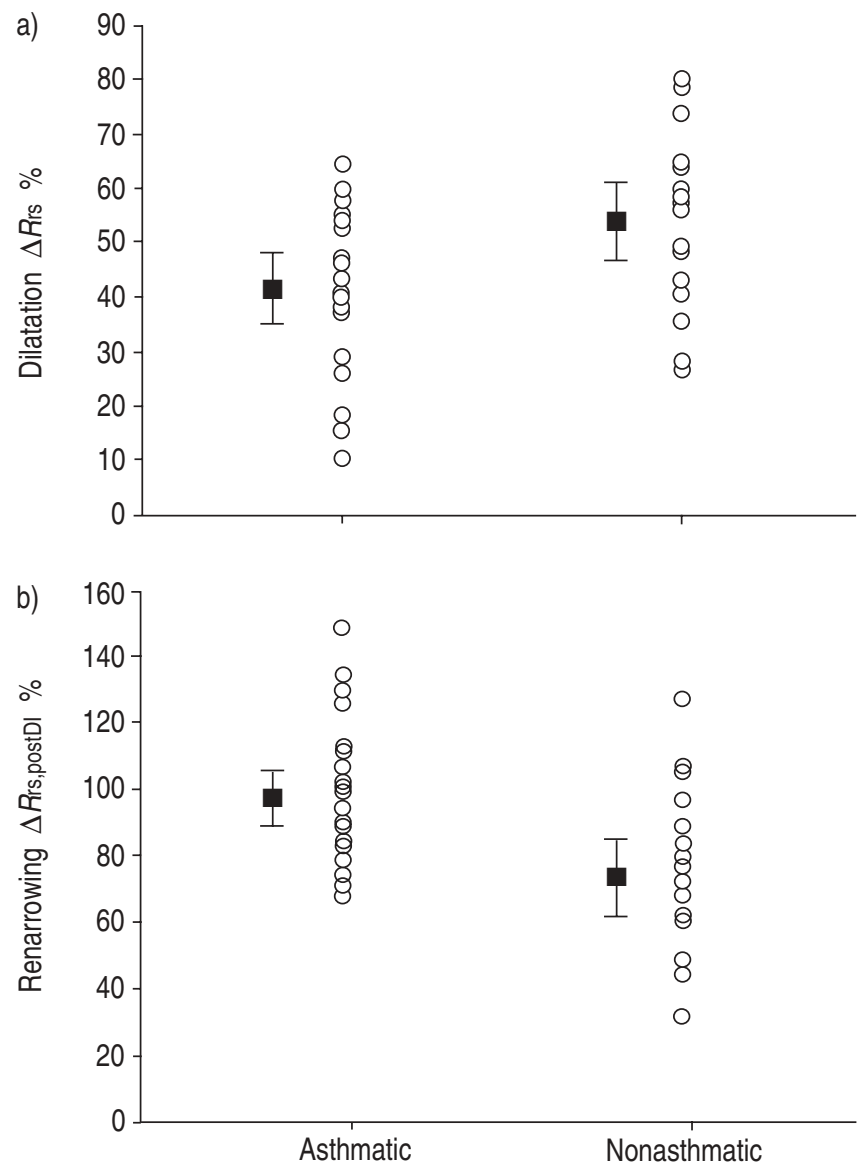

Fig. 2.-Deep inspiration induced dilatation in asthmatic and nonasthmatic subjects (a) and re-narrowing (b) after methacholine challenge. Rrs,postDI: respiratory system resistance immediatedly after deep inspiration. $\bigcirc$ : individual data and $\mathbf{\square}$ : mean and $95 \%$ confidence intervals.

dilatation of $60 \pm 7 \%(\mathrm{p}=0.0001)$. At TLC, $R$ rs was significantly greater in asthmatic than in nonasthmatic subjects $(\mathrm{p}=0.001)$.

Re-narrowing of the airways following DI-induced dilatation was significantly greater in the asthmatic than in the nonasthmatic subjects ( $\mathrm{p}=0.001)$ (fig. $2 \mathrm{~b}$ ). In the asthmatic subjects, mean $R r s$,exp was $6.3 \pm 0.8 \mathrm{cmH} \mathrm{C}_{2} \mathrm{O} \cdot \mathrm{L}^{-1} \cdot \mathrm{s}^{-1}$. Immediately after the DI, Rrs,postDI was $6.1 \pm 0.9 \mathrm{cmH}_{2} \mathrm{O} \cdot \mathrm{L}^{-1} \cdot \mathrm{s}^{-1}$, a

Table 1.-Subject characteristics and effect of methacholine challenge tests

\begin{tabular}{|c|c|c|c|}
\hline & Asthmatic & Nonasthmatic & p-value \\
\hline Subjects $\mathrm{n}$ & 25 & 18 & \\
\hline $\mathrm{M}: \mathrm{F}$ & $14: 11$ & $5: 13$ & $0.12^{\#}$ \\
\hline Age yrs & $46.5 \pm 5.9$ & $33.7 \pm 5.6$ & 0.001 \\
\hline Atopic & $21(85 \%)$ & $7(42 \%)$ & $0.006^{\#}$ \\
\hline Exhaled NO ppb & $24.3(17.2-34.4)$ & $12.4(9.6-16.1)$ & 0.005 \\
\hline FEV1 \% predicted & $83.3 \pm 5.7$ & $99.4 \pm 5.3$ & $<0.001$ \\
\hline Rrs,mean $\%$ predicted & $147.8 \pm 17.9$ & $111.2 \pm 15.9$ & 0.007 \\
\hline Baseline tidal volume L & $0.91 \pm 0.09$ & $0.86 \pm 0.09$ & 0.45 \\
\hline Baseline inspiratory capacity L & $2.56 \pm 0.26$ & $2.57 \pm 0.33$ & 0.97 \\
\hline $\mathrm{DRR} \%$ fall $\mathrm{FEV} 1 \cdot \mu \mathrm{mol}^{-1}$ & $14.4(8.6-22.9)$ & $0.26(0.09-0.44)$ & $<<0.001$ \\
\hline Methacholine dose $\mu \mathrm{mol}$ & $1.8(1.1-3.0)$ & $95.5(54.7-166.6)$ & $<<0.001$ \\
\hline Increase in $R$ rs,mean \% & $55.7 \pm 13.5$ & $68.0 \pm 22.9$ & 0.34 \\
\hline Decrease in FEV1 \% & $24.4 \pm 2.4$ & $15.0 \pm 3.0$ & $<0.001$ \\
\hline
\end{tabular}

Data are presented as mean $\pm 95 \%$ confidence interval (CI), geometric means $(95 \% \mathrm{CI})$, or $\mathrm{n}(\%$ positive skin-prick tests). p-Values are for the comparison between groups by unpaired t-test or Chi-squared test $\left.{ }^{\#}\right)$. M: male; F: female; NO: nitric oxide; ppb: parts per billion; FEV1: forced expiratory volume in one second; Rrs, mean: mean of all respiratory system resistance values obtained over 1 min of tidal breathing; DRR: doseresponse ratio; $<<$ : much less than. 
mean of $97 \pm 8 \%$ of pre-DI values, indicating that the airways of the asthmatic subjects had almost completely re-narrowed to their pre-DI calibre. In the nonasthmatic subjects, mean $R \mathrm{rs}$,exp was $5.8 \pm 0.9 \mathrm{cmH} \mathrm{C}_{2} \mathrm{O} \cdot \mathrm{L}^{-1} \cdot \mathrm{s}^{-1}$ and $R \mathrm{rs}$,postDI was $4.0 \pm$ $0.9 \mathrm{cmH}_{2} \mathrm{O} \cdot \mathrm{L}^{-1} \cdot \mathrm{s}^{-1}$, which was significantly lower than the pre-DI value $(\mathrm{p}=0.001)$. This value was $72 \pm 12 \%$ of the pre-DI value, indicating that in the nonasthmatic subjects re-narrowing was incomplete and the airways remained significantly dilated. The rate of re-narrowing, measured by calculating the time taken for $R$ rs, exp to return to within $90 \%$ of the pre-DI value, was significantly faster in asthmatic than nonasthmatic subjects $(12.8 \pm 5.1$ versus $36.1 \pm 11.2 \mathrm{~s}$, respectively, $\mathrm{p}<0.0001)$.

Tidal fluctuations in $R$ rs differed significantly between asthmatic and nonasthmatic subjects both at baseline $(\mathrm{p}=0.015)$ and after challenge $(\mathrm{p}=0.019)$, and increased in both asthmatic and nonasthmatic subjects following methacholine challenge (fig. 3). In the asthmatic subjects the mean tidal fluctuation in $R$ rs was $1.42 \pm 0.71 \mathrm{cmH} \mathrm{H}_{2} \mathrm{O} \cdot \mathrm{L}^{-1} \cdot \mathrm{s}^{-1}$ before challenge and $2.45 \pm 0.48 \mathrm{cmH}{ }_{2} \mathrm{O} \cdot \mathrm{L}^{-1} \cdot \mathrm{s}^{-1}$ after challenge $(\mathrm{p}<0.001)$. Similarly, in the nonasthmatic subjects, the mean tidal fluctuation increased from $0.93 \pm 0.53 \mathrm{cmH} \mathrm{O}_{2} \cdot \mathrm{L}^{-1} \cdot \mathrm{s}^{-1}$ prior to challenge $1.66 \pm 0.68 \mathrm{cmH}_{2} \mathrm{O} \cdot \mathrm{L}^{-1} \cdot \mathrm{s}^{-1}$ after challenge $(\mathrm{p}=0.01)$.

There were significant correlations between re-narrowing and dilatation after challenge and tidal fluctuation at baseline, prior to challenge. The extent of re-narrowing correlated with tidal fluctuation at baseline $(\mathrm{Rs}=0.52, \mathrm{p}=0.0004)$ (fig. 4a) but not after methacholine ( $\mathrm{Rs}=0.28, \mathrm{p}=0.07$ ) (fig. $4 \mathrm{~b}$ ). The extent of re-narrowing was inversely correlated with the magnitude of dilatation ( $\mathrm{R} s=-0.60, \mathrm{p}<0.0001)$ (fig. 5). The rate of renarrowing, measured as the time taken to return to $90 \%$ of pre-DI Rrs, correlated significantly with tidal fluctuation both at baseline ( $\mathrm{Rs}=-0.56, \mathrm{p}=0.0001)$ and after methacholine (Rs=-0.34, $\mathrm{p}=0.03$ ) and with dilatation $(\mathrm{Rs}=0.45, \mathrm{p}=0.003)$. Dilatation correlated with tidal fluctuation measured at baseline $(\mathrm{Rs}=-0.38, \mathrm{p}=0.01)$ but not after challenge $(\mathrm{Rs}=-0.25$, $\mathrm{p}=0.11$ ). Multiple linear regression analyses showed that both dilatation and baseline tidal fluctuations in Rrs were independent predictors of re-narrowing, in a model that also included the per cent increase in Rrs,mean after methacholine $\left(r^{2}=0.55\right.$, $\mathrm{p}<0.0001$ for the regression). Age, per cent decrease in inspiratory capacity (IC) and baseline Rrs,mean were not significant predictors in the model. There were significant correlations between airway responsiveness, measured as DRR, and renarrowing $(\mathrm{Rs}=0.37, \mathrm{p}=0.01)$, dilatation $(\mathrm{Rs}=-0.36, \mathrm{p}=0.02)$ and tidal fluctuation at baseline $(\mathrm{Rs}=0.36, \mathrm{p}=0.02)$.

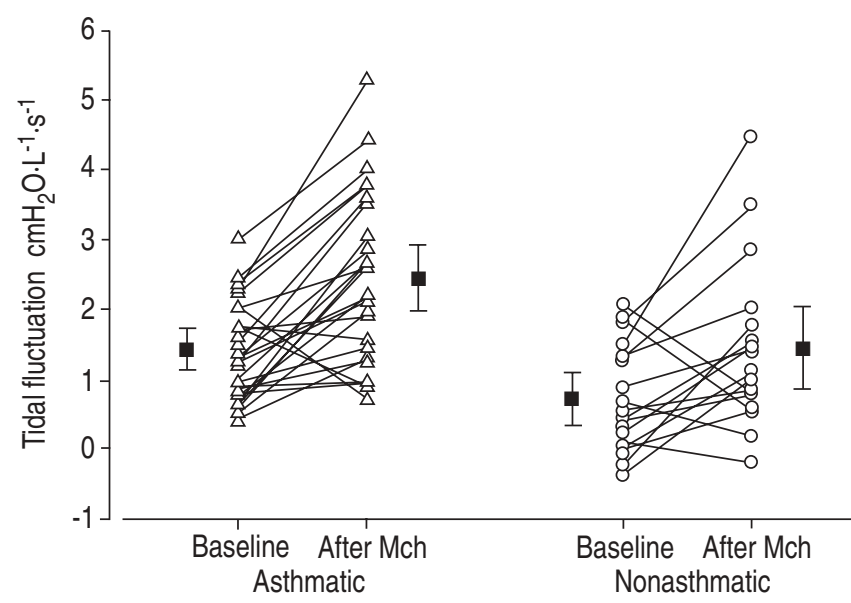

Fig. 3. - Tidal fluctuation at baseline and after methacholine (Mch) in asthmatic $(\triangle)$ and nonasthmatic $(\bigcirc)$ subjects. $\mathbf{0}$ : mean and $95 \%$ confidence intervals.
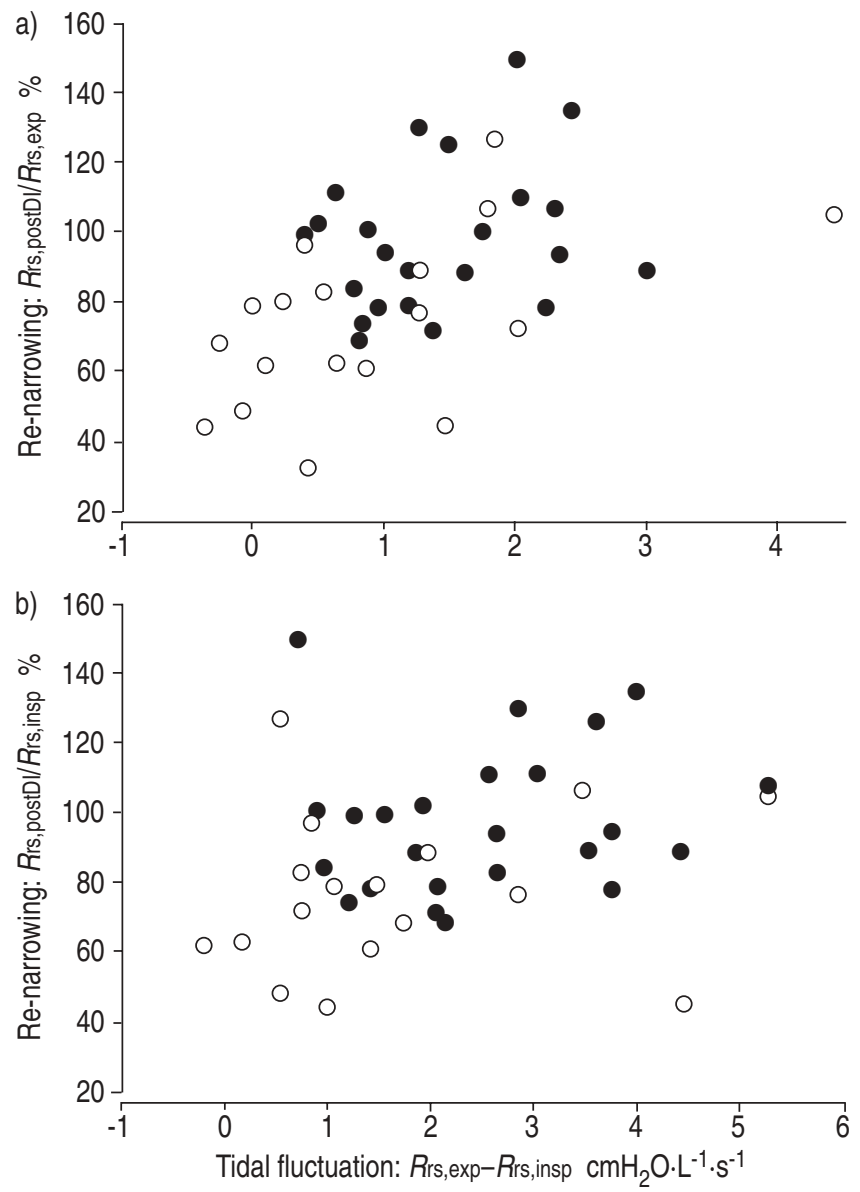

Fig. 4.-Relationship between tidal fluctuation in respiratory system resistance at baseline (a) and after methacholine challenge (Mch; b), and re-narrowing following deep inspiration-induced dilatation, in nonasthmatic $(\bigcirc)$ and asthmatic $(\bullet)$ subjects. For tidal fluctuations at baseline, the Spearman correlation coefficient $(\mathrm{Rs})=0.52 \quad(\mathrm{p}=0.0004)$ for all subjects, $R s=0.47 \quad(p=0.05)$ for nonasthmatics and $R s=0.31$ $(\mathrm{p}=0.14)$ for asthmatics. For tidal fluctuation after methacholine, $R s=0.28(p=0.07)$ for all subjects, $R s=0.15(p=0.55)$ for nonasthmatics and $\mathrm{Rs}=0.13(\mathrm{p}=0.54)$ for asthmatics. $R \mathrm{rs}$,postDI: respiratory system resistance $(R \mathrm{rs})$ immediatedly after deep inspiration; $R \mathrm{rs}$,exp: $R \mathrm{rs}$ at end-expiration; $R \mathrm{rs}$,insp: $R \mathrm{rs}$ at end-inspiration.

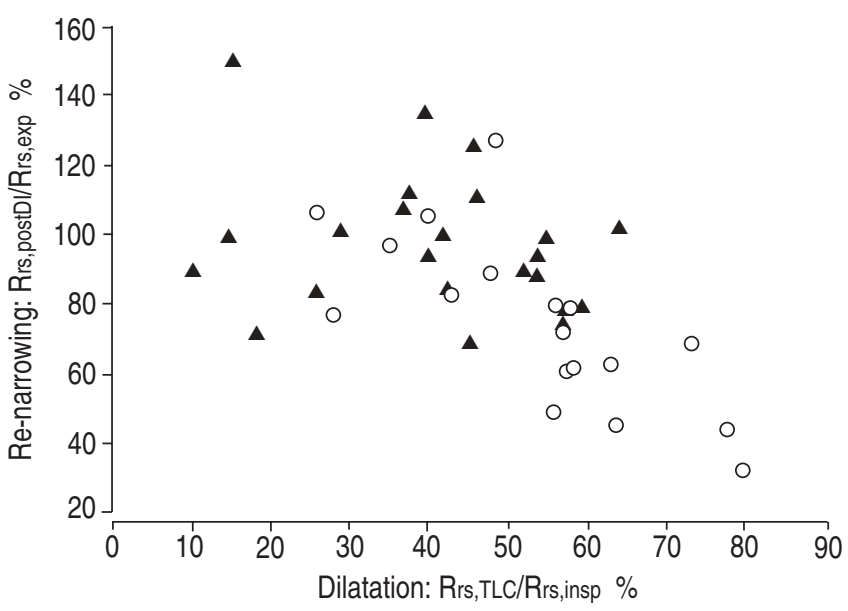

Fig. 5.-Relationship between deep inpiration-induced dilatation and re-narrowing in nonasthmatic $(\bigcirc)$ and asthmatic $(\boldsymbol{\Delta})$ subjects. Spearman correlation coefficient $=-0.83(\mathrm{p}<0.0001)$ for nonasthmatics, $0.31 \quad(\mathrm{p}=0.14)$ for asthmatics and $-0.60(\mathrm{p}<0.0001)$ for all subjects together.

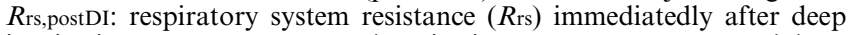
inspiration; Rrs,exp: Rrs at end-expiration; $R \mathrm{rs}, \mathrm{TLC}: R_{\mathrm{rs}}$ at total lung capacity; $R$ rs,insp: $R$ rs at end-inspiration. 


\section{Discussion}

In this study of the dynamic behaviour of the airways in asthmatic and nonasthmatic subjects, DI was found to cause significant dilatation in both asthmatic and nonasthmatic subjects, following methacholine challenge. However, the airways of the asthmatic subjects re-narrowed almost completely when the subjects expired back to FRC, whereas the airways of the nonasthmatic subjects remained significantly dilated. The rate of re-narrowing was significantly increased in the asthmatic subjects who took a shorter time to return to preDI resistance. Re-narrowing, measured either as the extent or rate, correlated significantly, and independently, with both the magnitude of DI-induced dilatation, and the magnitude of the volume-related fluctuations in respiratory resistance during tidal breathing at baseline, prior to methacholine challenge. The magnitude of re-narrowing, dilatation and baseline tidal fluctuation were all correlated with the dose-response ratio, a continuous measure of airway responsiveness.

There have been many previous reports of the differences between asthmatic and nonasthmatic subjects in residual dilatation following DI $[1,13,14]$. However, very few studies have distinguished between the magnitude of maximal dilatation and the extent of the subsequent re-narrowing. Differences in re-narrowing between asthmatic and nonasthmatic subjects were noted in a previous study [15] and specifically described in a preliminary report [16], but have only recently been studied in detail [4]. The accumulating evidence of real differences between asthmatic and nonasthmatic subjects in the rate of re-narrowing suggests that an improved understanding of the factors that determine re-narrowing may be pertinent to the understanding of the pathophysiology of asthma.

The association between re-narrowing and baseline tidal fluctuation in the present study is a new and potentially important finding. It implies that re-narrowing is determined in part by some property of the airways that exists prior to challenge and can be detected by the volume dependence of resistance during tidal breathing. The association is strong and it seems unlikely that it is due to any artefact or technical error. The methods for measuring resistance using the forced oscillation technique are standard, and the values for the nonasthmatic control subjects are within the predicted range [12]. There were significant differences in age between the asthmatic and nonasthmatic groups, but age was not a significant predictor of any of the main outcome variables, and omitting the data from asthmatic subjects aged $>60$ yrs had no effect on the outcomes of the study. There were also differences between groups in the effect of methacholine on lung volumes, indicated by a greater change in inspiratory capacity in the asthmatic group. However, the change in IC was not a significant factor in any of the predictive models. In calculating tidal fluctuation in resistance the authors used measurements at instants of zero flow, at end inspiration and end expiration, which allowed the volume dependent changes in resistance to be measured independently of any flow-related effects. Using a linear regression model, MARCHAL et al. [17] have also demonstrated the volume dependence of resistance during tidal breathing at baseline and after methacholine challenge in children with airway hyperresponsiveness to methacholine.

The differences in re-narrowing between asthmatic and nonasthmatic subjects are comparable with those that have been reported previously. In previous papers re-narrowing has been reported either as the rate $[15,16]$ or as the extent of re-narrowing present at FRC after the DI [4]. The current study has shown that there are significant differences between asthmatic and nonasthmatic subjects in both rate and extent of re-narrowing. In subjects in the current study, the reconstriction ratio as calculated by JENSEN et al. [4] differed significantly between asthmatic $(0.97 \pm 0.15)$ and nonasthmatic $(0.64 \pm 0.15)$ subjects and the values are similar to those reported previously. The authors have extended these previous findings to show there is substantial overlap in re-narrowing between asthmatic and nonasthmatic subjects, suggesting that renarrowing reflects a continuum of airway behaviour in the population.

The mechanism that determines re-narrowing has not yet been established. Findings that asthmatic and healthy subjects differ both in the magnitude of DI-induced dilatation and in the extent of the subsequent re-narrowing in the current study are in accord with those of JENSEN et al. [4]. These investigators concluded that these differences in behaviour between asthmatic and healthy airways might be attributable to an increase in the stiffness of asthmatic ASM, such that it is unable to stretch enough during a DI to break many actinmyosin cross-bridges. They suggest that rapid re-narrowing is a function of the viscoelastic properties of the ASM and airway wall. The current study has extended their findings, to show that there is an inverse correlation between the magnitude of dilatation and the extent of re-narrowing in nonasthmatic subjects. This lends some support to this proposed mechanism, but suggests it may be a more important determinant of re-narrowing in non-asthmatic than asthmatic subjects. However, the strong correlation that was found between renarrowing and baseline tidal fluctuation in resistance suggests that airway stiffness is probably not the only factor contributing to re-narrowing.

Theoretically, wide tidal fluctuations in resistance could indicate an increased capacity to stretch and dilate the airway during the inspiratory phase of tidal breathing. However, tidal fluctuation was greater in asthmatic than nonasthmatic subjects both in the current study and, apparently, in that of JENSEN et al. [4]. Since asthma is associated with reduced airway distensibility [18], and in the present study there was an inverse correlation between tidal fluctuation and DIinduced dilatation, it seems unlikely that dilatation during tidal inspiration would be greater in asthmatic than nonasthmatic airways. Alternatively, wide tidal fluctuations in resistance could reflect an increased capacity of the airways to narrow during the expiratory phase of tidal breathing. In the present study, tidal fluctuation was more closely related to changes occurring during expiration than during inspiration, since the variance in tidal fluctuation was better explained by resistance at end-expiration $\left(\mathrm{R}^{2}=0.73\right)$ than at end-inspiration $\left(\mathrm{R}^{2}=0.09\right)$. It might be argued that, if tidal fluctuation reflects airway narrowing during tidal expiration, this narrowing could be due to the passive recoil of the elastic airway such that stiffer airways, with greater recoil, re-narrow faster both during tidal breathing and following DI. However, if this were true it would be expected that the relationship between tidal fluctuation and re-narrowing would strengthen as ASM stiffness increased after methacholine. In fact, the authors found no increase in the strength of the association after methacholine. Furthermore, in the present study both tidal fluctuation and dilatation contributed independently to the models predicting re-narrowing, suggesting that they reflect different mechanisms. Taken together, these findings suggest that re-narrowing is determined not only by airway stiffness, indicated by the magnitude of DI-induced dilatation, but also by some other property that can be detected by the tidal fluctuation in resistance at baseline.

The nature of the airway property that determines the tidal fluctuation in resistance at baseline is unknown. Although it is not established whether active smooth muscle shortening occurs during tidal breathing, SOLwAY and FrEDBERG [19] have hypothesised that the dynamic changes in airway calibre 
during tidal breathing may be affected by ASM shortening velocity. They suggest that an increase in ASM shortening velocity would allow more shortening to occur during the expiratory phase of tidal breathing. While other factors, such as the magnitude of hysteresis of the lungs and airways, may also play a role in determining re-narrowing following DI, it seems possible that the association between re-narrowing following DI and tidal fluctuation in resistance reflects a similar underlying mechanism, such as ASM shortening velocity.

There are other possible mechanisms for the increased tidal fluctuation in resistance in asthmatic subjects, but these are unlikely to explain the relationship between tidal fluctuation and re-narrowing. Because resistance has a hyperbolic relationship with lung volume, it has been suggested that large tidal fluctuations in resistance in asthmatic subjects do not reflect large changes in airway calibre but are simply an amplification of small changes occurring in airways with high resistance [4]. This could explain the increase in tidal fluctuation that occurred after methacholine challenge in both asthmatic and nonasthmatic subjects. However, it is unlikely to explain the relationship between re-narrowing and tidal fluctuation at baseline, since any relationship due to high resistance at baseline should be strengthened when resistance is increased after methacholine challenge. Furthermore, if geometric factors are the most important determinant of tidal fluctuation, then it might be expected that $R$ rs, exp would be a better predictor of re-narrowing than tidal fluctuation. The contribution of laryngeal resistance to the resistance of the total respiratory system could differ between asthmatic and nonasthmatic subjects [20]. The larynx moves in phase with respiration and laryngeal resistance decreases in response to DI in both asthmatic and normal subjects [21]. Further studies are needed to measure the contribution of laryngeal movements to the dynamic changes in resistance measured by the forced oscillation technique. However, it seems unlikely that they could explain the relationship between re-narrowing and tidal fluctuation.

The finding that airway behaviour during both DI and tidal breathing was related to airway responsiveness, measured by the dose-response ratio, is in keeping with previous suggestions that an impaired response to DI could contribute to airway hyperresponsiveness [1]. FISH et al. [1] and OREHEK et al. [22] recognised that the FEV1 is determined by both the magnitude of airway narrowing as well as by the preceding DI. Airway responsiveness, measured using FEV1, would be increased in subjects with airways that have both an impaired ability to dilate and an increased rate of re-narrowing during expiration. Differences in dilatation during DI may explain why the asthmatic subjects in the present study had significantly greater falls in FEV1 following methacholine than did the nonasthmatic subjects, despite having similar changes in $R$ rs.

In summary, this study has reaffirmed that, after methacholine-induced bronchoconstriction, both the magnitude of dilatation induced by deep inspiration and speed of the subsequent airway re-narrowing differ in asthmatic and nonasthmatic subjects. Furthermore, the authors found that re-narrowing is related not only to the magnitude of the dilatation but also to the volume dependent tidal fluctuation in resistance during tidal breathing, at baseline prior to challenge. This suggests that several different mechanisms may contribute to re-narrowing, including the effects of methacholine on airway smooth muscle stiffness or airway closure, as well as some property of the airways that exists prior to challenge. Although the authors did not determine the nature of this baseline abnormality, the possibilities include an increase in airway smooth muscle shortening velocity, due either to altered parenchymal tethering, abnormal lung elastic recoil or altered cross-bridge dynamics. While further studies of the factors that affect the dynamic behaviour of the airways in asthma are needed, the possibility that abnormal airway behaviour could be detected at baseline during tidal breathing is intriguing [23].

\section{References}

1. Fish JE, Ankin MG, Kelly JF, Peterman VI. Regulation of bronchomotor tone by lung inflation in asthmatic and nonasthmatic subjects. J Appl Physiol 1981; 50: 10791086.

2. Lim TK, Pride NB, Ingram RHJ. Effects of volume history during spontaneous and acutely induced airflow obstruction in asthma. Am Rev Respir Dis 1987; 135: 591-596.

3. Pellegrino R, Wilson O, Jenouri G, Rodarte JR. Lung mechanics during induced bronchoconstriction. J Appl Physiol 1996; 81: 964-975.

4. Jensen A, Atileh H, Suki B, Ingenito EP, Lutchen KR. Airway caliber in healthy and asthmatic subjects: effects of bronchial challenge and deep inspirations. J Appl Physiol 2001; 91: 506-515.

5. Fredberg JJ, Inouye DS, Mijailovich SM, Butler JP. Perturbed equilibrium of myosin binding in airway smooth muscle and its implication in bronchospasm. Am J Respir Crit Care Med 1999; 159: 959-967.

6. Yan K, Salome CM, Woolcock AJ. Rapid method for the measurement of bronchial responsiveness. Thorax 1983; 38: $760-765$

7. Chai H, Farr RS, Froehlich LA, et al. Standardisation of bronchial inhalation challenge procedures. J Allergy Clin Immunol 1975; 56: 323-327.

8. Boonsawat W, Salome CM, Woolcock AJ. Effect of allergen inhalation on the maximal response plateau of the doseresponse curve to methacholine. Am Rev Respir Dis 1992; 146: 565-569.

9. O'Connor G, Sparrow D, Taylor D, Segal M, Weiss S. Analysis of dose response curves to methacholine. An approach suitable for population studies. Am Rev Respir Dis 1987; 136: 1412-1417.

10. Peat JK, Salome CM, Berry G, Woolcock AJ. Relation of dose-response slope to respiratory symptoms and lung function in a population study of adults living in Busselton, Western Australia. Am Rev Respir Dis 1992; 146: 860-865.

11. Morris J, Koski A, Johnson L. Spirometric standards for healthy non-smoking adults. Am Rev Respir Dis 1971; 103: 57-67.

12. Pasker HG, Mertens I, Clement J, Van de Woestijne KP. Normal values of total respiratory input resistance and reactance for adult men and women. Eur Respir Rev 1994; 4: 134-137.

13. Burns CB, Taylor WR, Ingram RH. Effects of deep inhalation in asthma; relative airway and parenchymal hysteresis. J Appl Physiol 1985; 59: 1590-1596.

14. Brusasco V, Crimi E, Barisone G, Spanevello A, Rodarte JR, Pellegrino R. Airway responsiveness to methacholine: effects of deep inhalations and airway inflammation. J Appl Physiol 1999; 87: 567-573.

15. Pellegrino R, Violante B, Brusasco V. Maximal bronchoconstriction in humans: relationship to deep inhalation and airway sensitivity. Am J Respir Crit Care Med 1996; 153: $115-121$.

16. Jackson AC, Rassulo J, Marquina J, Celli B. Influence of deep inspiration on methacholine $(\mathrm{MCH})$ induced bronchoconstriction. Am J Respir Crit Care Med 1999; 159: 468.

17. Marchal F, Loos N, Monin P. Methacholine-induced volume dependence of respiratory resistance in preschool children. Eur Respir J 1999; 14: 1167-1174.

18. Ward C, Johns DP, Bish R, et al. Reduced airway distensibility, fixed airflow limitation, and airway wall 
remodelling in asthma. Am J Respir Crit Care Med 2001; 164: 1718-1721.

19. Solway J, Fredberg JJ. Perhaps airway smooth muscle dysfunction contributes to asthmatic bronchial hyperresponsiveness after all. Am J Respir Cell Mol Biol 1997; 17: 144 146.

20. Shindoh C, Sekizawa K, Hida W, Sasaki H, Takishima T. Upper airway response during bronchoprovocation and asthma attack. Am Rev Respir Dis 1985; 132: 671-678.

21. Sekizawa K, Yanai M, Sasaki H, Takishima T. Effect of a previous voluntary deep breath on laryngeal resistance in normal and asthmatic subjects. J Appl Physiol 1987; 63: 1406-1412.

22. Orehek J, Nicoli MM, Delpierre S, Beaupre A. Influence of the previous deep inspiration on the spirometric measurement of provoked bronchoconstriction in asthma. Am Rev Respir Dis 1981; 123: 269-272.

23. Que C-L, Maksym G, Macklem PT. Deciphering the homeokinetic code of airway smooth muscle. Am J Respir Crit Care Med 2000; 161: 161-163. 